\title{
Biliary lipids, bile acids and gallstone formation in hypovitaminotic $\mathbf{C}$ guinea-pigs
}

\author{
BY S. A. JENKINS \\ J. A. Pye Research Centre, Walnut Tree Manor, Haughley Green, Stowmarket, \\ Suffolk IPI4 $3 R S$
}

(Received 19 August 1977 - Accepted 26 January 1978)

I. Hypovitaminotic $\mathrm{C}$ guinea-pigs fed on a high-cholesterol diet for 5 weeks developed gallstones ( $810 \mathrm{mg}$ cholesterol $/ \mathrm{g}$ ) whereas no concretements were observed in vitamin $\mathrm{C}$-replete animals.

2. Scanning electron microscope studies of the three types of gallstone observed in the gallbladders of vitamin C-deficient animals showed them to be composed of randomly-arranged needle-shaped or laminated crystals of cholesterol.

3. The hepatic bile of gallstone-forming animals had a higher cholesterol concentration and lower bile acid content, the latter being principally due to a reduction in the chenodeoxycholic fraction, than the bile of vitamin C-replete animals.

4. No significant difference was observed between the volume of bile secreted by hypovitaminotic $C$ and vitamin C-replete animals, but due to the qualitative changes in bile composition, gallstone formation was associated with an increased biliary secretion of cholesterol and a reduced secretion of bile acids.

Since most gallstones form in the gallbladder and seldom recur after cholecystectomy, the gallbladder may play an important role in the aetiology of cholelithiasis. However, the secretion of bile abnormal with respect to cholesterol solubility has been observed after cholecystectomy (Small \& Rapo, I970; Almond, Vlahcevic, Bell, Gregory \& Swell, I973) and has led to the suggestion that cholelithiasis results from a subtle metabolic defect of the liver (Small, 1970; Small \& Rapo, 1970; Vlahcevic, Bell \& Swell, 1970). Recently, reduced values for bile acid : cholesterol and for phospholipid:cholesterol concomitant with cholesterol gallstone formation have been reported in the gallbladder bile of hypovitaminotic $\mathrm{C}$ guinea-pigs fed on a high-cholesterol diet (Jenkins, 1977). The following study was undertaken to establish whether or not cholelithiasis and the accompanying changes in the composition of the gallbladder bile of these animals may have resulted from an abnormality in the secretion of biliary lipids and bile acids by the liver.

\section{EXPERIMENTAL}

\section{Animals and diets}

Twenty-six male guinea-pigs (Dunkin Hartly, Redfern Animal Breeders Ltd, Brenchley, Kent) aged $\mathrm{I} 8 \mathrm{~d}$ and weighing approximately $200 \mathrm{~g}$ were housed two animals per cage and allowed access to food and water ad lib. On arrival from the supplier the animals were fed on a standard guinea-pig chow for 2 weeks to accustom them to their surroundings. Thereafter the guinea-pigs were fed on a high-cholesterol scorbutic diet (Cooper Nutrition Products, Ltd Witham, Essex), the composition of which is shown in Table r. Because it is difficult to distinguish between the metabolic consequences of inanition induced by vitamin $\mathrm{C}$ deficiency and vitamin $\mathrm{C}$ deficiency per se, a state of chronic hypovitaminosis $\mathrm{C}$ was induced in thirteen of the animals by the daily peroral administration of only $0.5 \mathrm{mg}$ L-ascorbic acid (Sigma, Ltd, Kingston upon Thames, Surrey) in $0.2 \mathrm{ml}$ sucrose $(200 \mathrm{~g} / \mathrm{l})$. The remaining animals were similarly dosed with $5.0 \mathrm{mg}$ of the vitamin in the same volume of sucrose. 
Table I. Composition $(\mathrm{g} / \mathrm{kg})$ of the vitamin C-deficient diet fed to the guinea-pigs

$\begin{array}{lc}\text { Vitamin-free casein } & 100 \\ \text { Gelatine } & 100 \\ \text { Maize starch } & 427 \\ \text { Sucrose } & \text { IOO } \\ \text { Hydrogenated coconut oil } & 50 \\ \text { Cholesterol } & 5 \\ \text { Cellulose powder } & \text { I } 70 \\ \text { L-arginine hydrochloride } & 2 \cdot 5 \\ \text { DL-methionine } & 1 \cdot 5 \\ \text { L-lysine hydrochloride } & \text { I } \\ \text { Mineral supplement* } & 40 \\ \text { Vitamin premix } \dagger & 3\end{array}$

* US Pharmacopoeia (1965).

† Retinol $30 \mathrm{mg}$; ergocalciferol $550 \mu \mathrm{g}$; $\alpha$-tocopherol $1000 \mathrm{mg}$; menapthone $300 \mathrm{mg}$; thiamin $100 \mathrm{mg}$; riboflavin $100 \mathrm{mg}$; nicotinic acid $1000 \mathrm{mg}$; pantothenic acid $500 \mathrm{mg}$; pyridoxine $100 \mathrm{mg}$; inositol $500 \mathrm{mg}$; p-amino-benzoic acid $500 \mathrm{mg}$; biotin $4 \mathrm{mg}$; folic acid $40 \mathrm{mg}$; choline $16.5 \mathrm{~g}$; cyanocobalamin $300 \mu \mathrm{g}$; maize starch $79 \cdot 3 \mathrm{~g}$.

\section{Experimental procedure}

After 5 weeks on the scorbutic diet the guinea-pigs were fasted overnight, weighed, anaesthetized by an intraperitoneal injection of Sagatal (May and Baker Ltd, Dagenham, Essex), and the biliary tree inspected for concretements. After ligation of the cystic duct the gallbladder was removed and the contents centrifuged for $20 \mathrm{~min}$ to separate the bile from gallstones and associated debris. A polyethylene cannula (3FG; Portex Ltd, Hythe, Kent) was inserted into the common bile duct and biliary drainage continued for $15 \mathrm{~min}$.

\section{Analytical methods}

Bile phospholipids were determined by the method of Zilversmit \& Davis (1950) and cholesterol by the method of Watson (1960) after digitonin-precipitation and reconstitution in distilled water. Bile acids were determined by gas-liquid chromatography (Klassen, 197I) after enzymic hydrolysis with Clostridium welchii powder (Grade III; Sigma Ltd, Kingston upon Thames, Surrey).

The gallstones and associated debris were pooled, washed in distilled water and dried under vacuum. A small sample of each type of stone present was coated with gold under vacuum and examined by scanning electron microscopy (Cambridge $\mathrm{S}_{4}$-ro; Cambridge Scientific Instruments Ltd, Cambridge). The remaining gallstones were extracted with ethanol $(700 \mathrm{ml} / \mathrm{l})$, and a portion of the extract partitioned between ethanol and petroleum spirit (bp $60-80^{\circ}$ ). The upper phase was analysed for cholesterol in the same manner as described previously for the bile.

\section{Statistical methods}

The statistical significance of any differences between control and experimental groups was evaluated using a Student's $t$ test; $P>0.05$ being regarded as statistically insignificant.

\section{RESULTS}

Gallstones (810 mg cholesterol/g) were present in the gallbladders and occasionally in the lumen of both the cystic and common bile duct of ten of the twelve survivors in the hypovitaminotic $\mathrm{C}$ group, whereas no concretements occurred in the guinea-pigs receiving $5.0 \mathrm{mg}$ ascorbic acid/d. 
Table 2. Total bile acid, cholesterol and phospholipid content of the hepatic bile of guinea-pigs receiving 0.5 or $5 \mathrm{mg}$ ascorbic acid/d

(Mean values with their standard errors; values in parentheses indicate no. of animals/treatment)

$\begin{array}{cccccc}\begin{array}{c}\text { Daily dosage } \\ \text { of ascorbic } \\ \text { acid (mg) }\end{array} & \begin{array}{c}\text { Bile acids } \\ \text { (BA) }\end{array} & \begin{array}{c}\text { Cholesterol } \\ \text { (C) }\end{array} & \begin{array}{c}\text { Phospholipids } \\ (\mathrm{P})\end{array} & \text { BA:C } & \text { P:C } \\ 5 \quad(13) & 6.85 \pm 0.45^{*} & 0.39 \pm 0.07^{*} & 1.93 \pm 0.20 & 17.56^{*} & 4.95^{*} \\ 0.5(12) & 4.81 \pm 0.41^{*} & 0.79 \pm 0.12^{*} & 1.90 \pm 0.14 & 6.08^{*} & 2.41^{*}\end{array}$

* Difference between treatments was statistically significant: $P<0.0$.

Table 3. Hepatic bile acid profile of guinea-pigs receiving either 0.5 or $5 \mathrm{mg}$ ascorbic acid/d

(Mean values with their standard errors; values in parentheses indicate no. of animals/treatment)

$\begin{array}{ccc}\begin{array}{c}\text { Daily dosage } \\ \text { of ascorbic } \\ \text { acid (mg) }\end{array} & \begin{array}{c}\text { Chenodeoxycholic } \\ \text { acid }\end{array} & \begin{array}{c}7-\text { Oxolithocholic } \\ \text { acid }\end{array} \\ 5 \text { (1 3) } & 4.09 \pm 0.31^{*} & 2.76 \pm 0.29 \\ 0.5 \text { (1 2) } & 2.39 \pm 0.23^{*} & 2.43 \pm 0.22\end{array}$

* Difference between treatments was statistically significant: $P<0.01$.

The most common type of concretement found in the gallbladders of hypovitaminotic $\mathrm{C}$ guinea-pigs were small sand-like particles, yellowish white in colour. Scanning electron microscopy of these small particles revealed two major morphological types. The first consisted of aggregates of irregularly-arranged needle-shaped crystals of cholesterol, associated with what appeared to be cellular debris (Plates I and 2). The second type, slightly larger in size, were composed of more compact aggregates of laminated crystals of cholesterol (Plate 3). Smaller clusters of crystals of bilirubin were often observed in association with the laminated cholesterol crystals.

In addition to the small sand-like particles, larger amorphous stones were also present in the gallbladders of hypovitaminotic $C$ guinea-pigs. These stones appeared to be formed by the fusion of the smaller aggregates of laminated cholesterol crystals (Plate 4 ). The surfaces of the aggregates of cholesterol crystals were irregularly orientated and often rounded (Plate 5).

Hepatic bile from the chronic hypovitaminotic $\mathrm{C}$ group contained significantly more cholesterol $(P<0.0 \mathrm{I})$ and significantly less bile acids $(P<0.0 \mathrm{I})$ than that of the vitamin $\mathrm{C}$ replete group, whereas the phospholipid content did not differ significantly (Table 2 ). The reduction in bile acid concentration was due principally to a reduced chenodeoxycholic acid (CDC) content, no significant difference in the 7-oxolithocholic $(7-\mathrm{OL})$ concentration being observed between the groups (Table 3 ).

No significant difference was observed between the volume of bile secreted by the hypo vitaminotic $\mathrm{C}(270 \pm 14.2 \mathrm{ml} / \mathrm{kg}$ body-weight per $24 \mathrm{~h})$ and vitamin C-replete $(266.7 \pm \mathrm{I} 6$. $\mathrm{ml} / \mathrm{kg}$ body-weight per $24 \mathrm{~h}$ ) animals. However, since the hepatic bile of the vitamin $\mathrm{C}$ deficient group of animals possessed a significantly higher cholesterol content and a signif cantly lower bile acid content, hypovitaminosis $\mathrm{C}$ in the guinea-pig is associated with decreased secretion of bile acids and an increased secretion of cholesterol (Fig. I). 

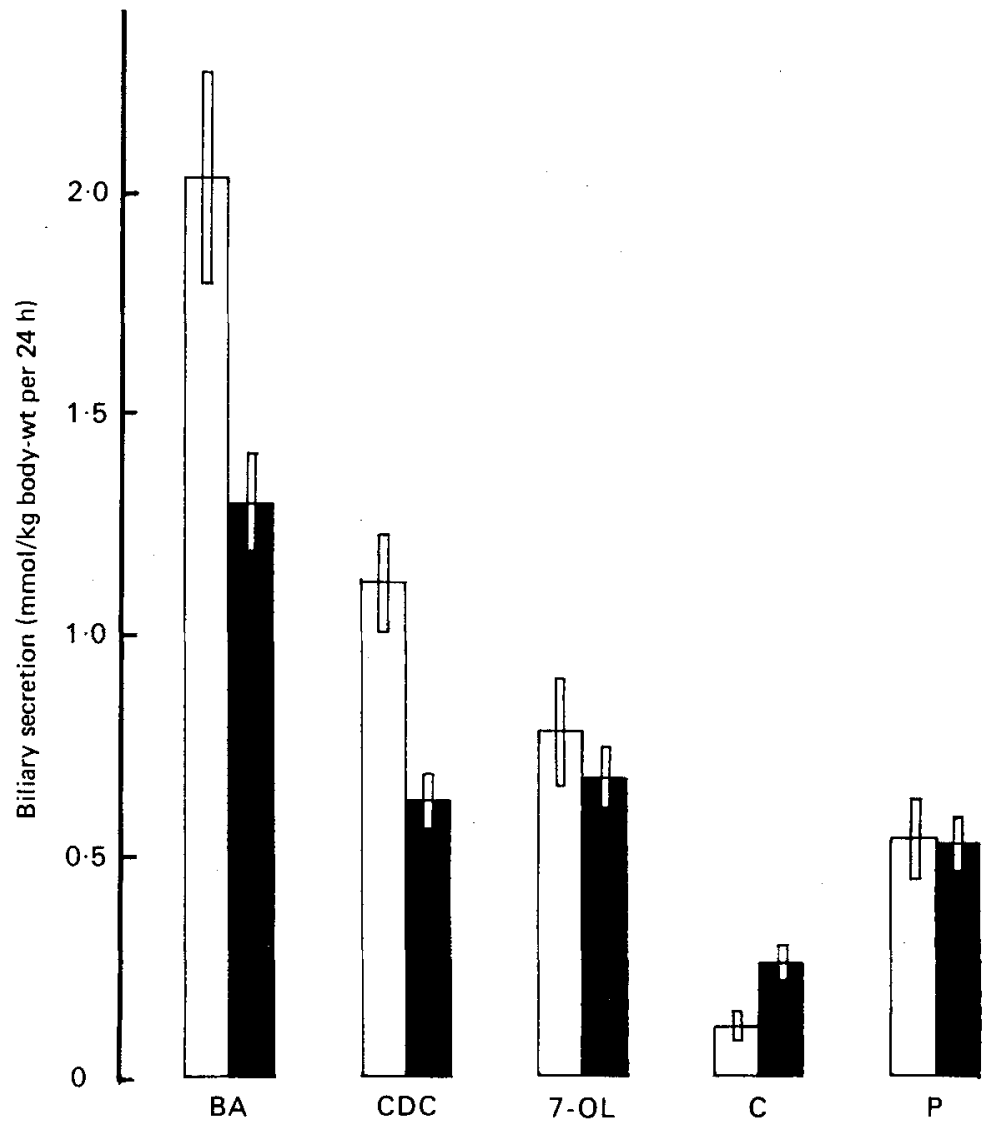

Fig. 1. Biliary secretion (mmol $/ \mathrm{kg}$ body-weight per $24 \mathrm{~h}$ ) of cholesterol $(\mathrm{C})$, phospholipids $(\mathrm{P})$, total bile acids (BA), chenodeoxycholic acid (CDC) and 7-oxolithocholic acid (7-OL) by guinea-pigs receiving $0.5(\square)$ or $5(\square) \mathrm{mg}$ ascorbic acid/d. Standard errors of the means are represented by vertical bars.

\section{DISCUSSION}

Scanning electron microscope studies of the gallstones found in hypovitaminotic $\mathrm{C}$ guineapigs showed them to be composed of aggregates of needle-shaped or laminated cholesterol crystals. Therefore the structure of the stones was essentially similar to that of human (Ogata \& Murata, 197I) and monkey gallstones (Osuga, Portman, Mitamura \& Alexander, I974).

Most gallstones appear to form de novo in the gallbladder and not in the hepatic ducts, but little is known of the factors which promote crystallization of cholesterol. In the present study, the smallest concretements, i.e. needle-shaped aggregates of cholesterol, appeared to be associated with cellular debris, suggesting that the latter might serve as nucleating factors for crystal formation. However, this finding does not exclude other factors such as mucus, precipitated inorganic compounds, bile pigments, bacteria etc. from being contributory to crystallization.

Like nucleation the process of gallstone growth is complex and poorly understood. The large amorphous stones found in the gallbladders of hypovitaminotic $\mathrm{C}$ guinea-pigs appeared to be formed by the fusion of smaller clusters of cholesterol crystals. However, fusion of smaller concretements may not be the only process by which stones increase their size, since the irregular orientation and rounded appearance of the crystals on their surface suggested 
that there is repeated growth and dissolution. Presumably, growth occurs when conditions favour precipitation rather than dissolution. Similar conclusions were reached by Osuga et al. (1974) in their morphological study of gallstone development in the squirrel monkey (Saimiri sciureus).

Gallstone formation in hypovitaminotic $\mathrm{C}$ guinea-pigs was associated with an increased biliary secretion of cholesterol and a reduced secretion of bile acids. Although the hepatic bile of gallstone-forming guinea-pigs is less concentrated than the gallbladder bile, the former may still be saturated with cholesterol, since, in a dilute solution, proportionally less bile salts form micelles and proportionally more are present as individual ions (Dowling, Mack \& Small, I97I). It is customary to express the relative molar concentrations of bile salts, phospholipids and cholesterol on triangular co-ordinates so that a single point of composition is obtained which can be related to a curve of maximum cholesterol solubility (Admirand \& Small, r968). It is not possible to use this method to decide whether or not the hepatic bile was saturated with cholesterol, since guinea-pig bile contains considerable amounts of 7-OL for which a solubility limit with which experimental values can be compared is not available at present. Nevertheless, it seems likely that an increased biliary secretion of cholesterol and a decreased secretion of bile acids is responsible for the qualitative changes in the composition of gallbladder bile and cholelithiasis in hypovitaminotic C guinea-pigs (Jenkins, I977).

Only two bile acids are present in guinea-pig bile in any readily measurable quantities, $\mathrm{CDC}$ and 7 -OL. The former. is a primary bile acid formed from cholesterol in the liver, while the latter is a secondary bile acid formed by bacterial modification of CDC in the intestine. Hypovitaminosis $\mathbf{C}$ in the guinea-pig is associated with a decreased secretion of $\mathrm{CDC}$, no significant change being observed in the secretion of $7-\mathrm{OL}$. Therefore it would appear that neither the formation of $7-\mathrm{OL}$ from $\mathrm{CDC}$ by anaerobic bacteria in the intestine nor its subsequent absorption is influenced by vitamin $\mathrm{C}$-deficiency. It is not possible to evaluate whether the reduced value for $\mathrm{CDC}: 7-\mathrm{OL}$ in hypovitaminotic $\mathrm{C}$ guinea-pigs resulting from a reduced secretion of $\mathrm{CDC}$ contributes to gallstone formation, since no information is available on the solubility limits or solubilizing capacity of $7-\mathrm{OL}$.

The reduction in the secretion of CDC by the vitamin C-deficient guinea-pig suggested an impaired ability of the liver to synthesize bile acids. Although hepatic synthesis of bile acids from cholesterol occurs by a complex series of reactions the rate-limiting step appears to be the cytochrome P450-dependant (Boyd \& Percy-Robb, I97I) 7 $\alpha$-hydroxylase (EC I.3.I.2I) system (Lindstedt, 1957), a diminished activity of which has been reported in gallstone-forming humans (Coyne, Bonorris, Goldstein \& Schoenfield, 1976). A reduction in the concentration (Degkwitz \& Staudinger, 1974) or activity (Fielding \& Hughes, 1975) of cytochrome $P 450$ in scorbutic guinea-pigs offers a possible explanation whereby vitamin $\mathrm{C}$-deficiency might influence $7 \alpha$-hydroxylase activity, and hence bile acid synthesis.

Shefer, Hauser, Lapar \& Mosbach (1973) observed that in the rat taurochenodeoxycholate markedly inhibited hydroxymethyl glutaryl-CoA reductase (HMGCoA reductase; EC I.I.I.34), the rate-limiting enzyme controlling cholesterol synthesis. Similarly, in humans, the increased activity of HMGCoA reductase in gallstone-forming patients (Salen, Nicolau, Shefer \& Mosbach, 1975) is inhibited by CDC feeding (Salen, Nicolau \& Shefer, 1973). In the vitamin C-deficient guinea-pig, a decreased conversion of cholesterol to CDC may result in an increased activity of $\mathrm{HMGCOA}$ reductase with a corresponding increase in endogenous cholesterol production. Consequently, the observed increase in the biliary secretion of cholesterol in the hypovitaminotic $\mathrm{C}$ guinea-pig may result from an increased activity of $\mathrm{HMGCoA}$ reductase, a reduction in the activity of $7 \alpha$-hydroxylase, or a combination of these effects. 
In conclusion, therefore, it would appear that in chronic hypovitaminosis $\mathrm{C}$ in the guineapig, an impaired bile acid synthesis, possibly accompanied by an increased synthesis of cholesterol, results in the secretion of hepatic bile abnormal with respect to cholesterol solubility, and cholelithiasis.

The author would like to thank Dr G. M. Murphy (Gastroenterology Unit, Guys Hospital, London SE2) for valuable advice and encouragement; Dr S. J. Ball (North East London Polytechnic, Stratford, London $\mathrm{E}_{15}$ ) for arranging the use of the scanning electron microscope, and the late Mr J. A. Rawlings and Mr C. Walker for technical assistance.

\section{REFERENCES}

Admirand, W. H. \& Small, D. M. (I968). J. clin. Invest. 47, 1043.

Almond, H. R., Vlahcevic, Z. R., Bell, C. C., Gregory, D. H. \& Swell, L. (1973). New. Engl. J. Med. 289 , I 213.

Boyd, G. S. \& Percy-Robb, I. W. (197I). Am. J. Med. 5I, 580.

Coyne, M. J., Bonorris, G. G., Goldstein, L. I. \& Schoenfield, L. J. (1976). J. Lab. clin. Med. 87, 281.

Degkwitz, E. \& Staudinger, H. J. (1974). In Vitamin C, p. I6r [G. G. Birch and K. Parker, editors]. London: Applied Science.

Dowling, R. H., Mack, E. \& Small, D. M. (1971). J. clin. Invest. 50, 1917.

Fielding, A. M. \& Hughes, R. E. (1975). Experientia 31, I 394.

Jenkins, S. A. (1977). Biochem. biophys. Res. Commun. 77, 1030.

Klassen, C. D. (1971). Clinica chim. Acta. 35, 225.

Lindstedt, S. (1957). Acta. chem. scand. 11, 417.

Ogata, T. \& Murata, F. (197I). Tohoku J. exp. Med. 104, 25.

Osuga, T., Portman, O. W., Mitamura, K. \& Alexander, B. S. (1974). Lab. Invest. $30,486$.

Salen, G., Nicolau, G. \& Shefer, S. (1973). Clin. Res. 21, 253.

Salen, G., Nicolau, G., Shefer, S. \& Mosbach, E. H. (1975). Gastroenterology 69, 676.

Shefer, S., Hauser, S., Lapar, V. \& Mosbach, E. H. (1973). J. Lipid Res. 14, 573.

Small, D. M. (1970). Adv. int. Med. 16, 243.

Small, D. M. \& Rapo, S. (1970). New Engl. J. Med. 258, 23.

US Pharmacopoeia (I965). XVII, p. 862.

Vlahcevic, Z. R., Bell, C. C. Jr \& Swell, L. (I970). Gastroenterology 59, 62.

Watson, D. B. (1960). Clinica chim. Acta. 5, 637.

Zilversmit, D. B. \& Davis, A. K. (1950). J. Lab. clin. Med. 35, I55.

\section{EXPLANATION OF PLATES}

Plate I. Scanning electron photomicrograph of the small sand-like concretements found in the gallbladder of hypovitaminotic $\mathrm{C}$ guinea-pigs, showing the irregular arrangement of needle-shaped cholesterol crystals. Plate 2. High magnification of a portion of Plate I showing the association between cholesterol crystals and cellular debris.

Plate 3. Scanning electron photomicrograph of a cluster of laminated cholesterol crystals forming the larger type of sand-like concretement. An aggregate of smaller bilirubin crystals (B) can be seen associated with the cholesterol crystals.

Plate 4. Scanning electron photomicrograph of the surface of the large amorphous stones. The stone is composed of clusters of smaller aggregates of laminated cholesterol crystals.

Plate 5. Higher magnification of a portion of Plate 4 showing the irregular orientation and rounded appearance of the aggregates of cholesterol crystals. 


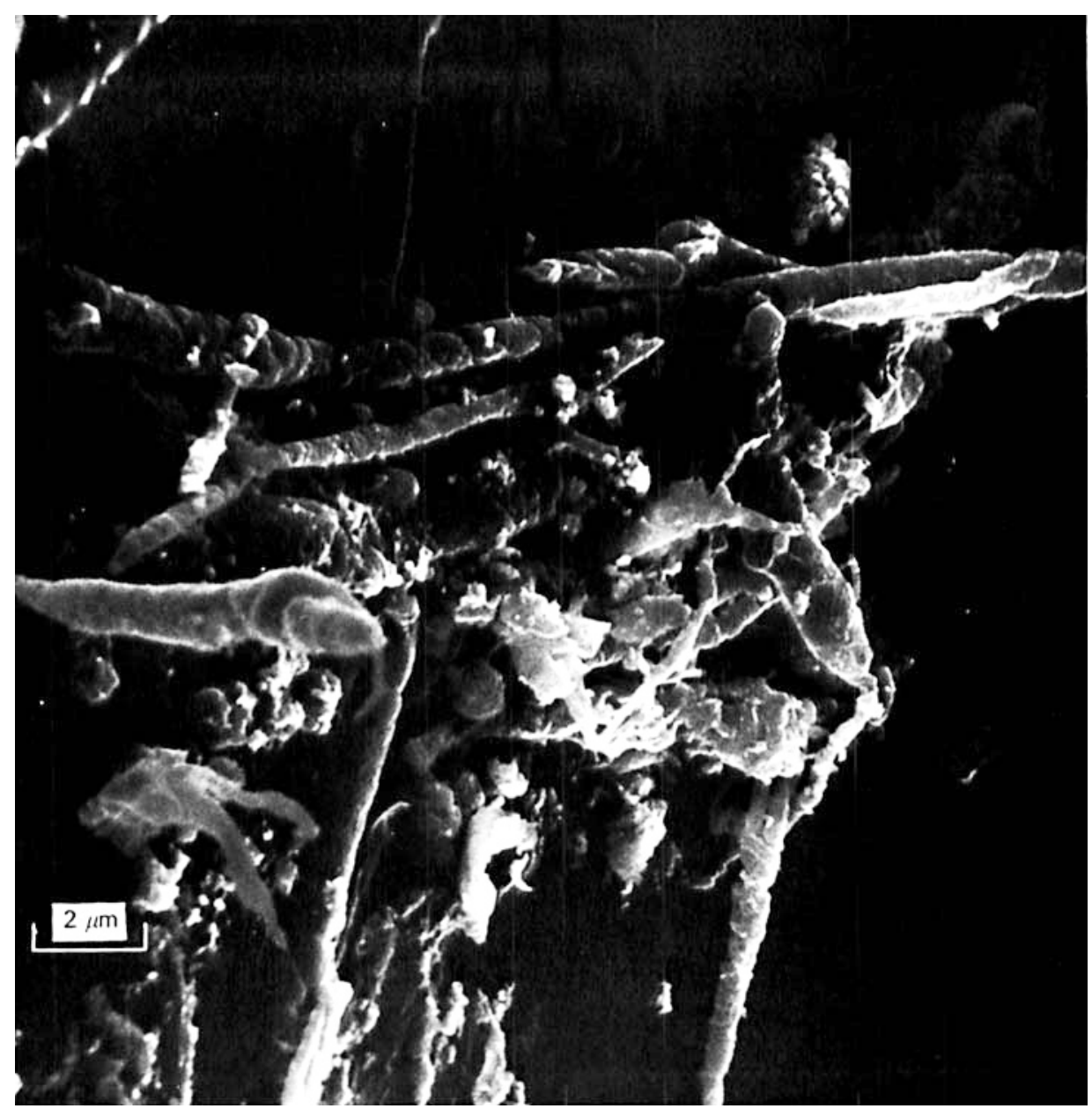


British Journal of Nutrition, Vol. 40, No. 2

Plate 2

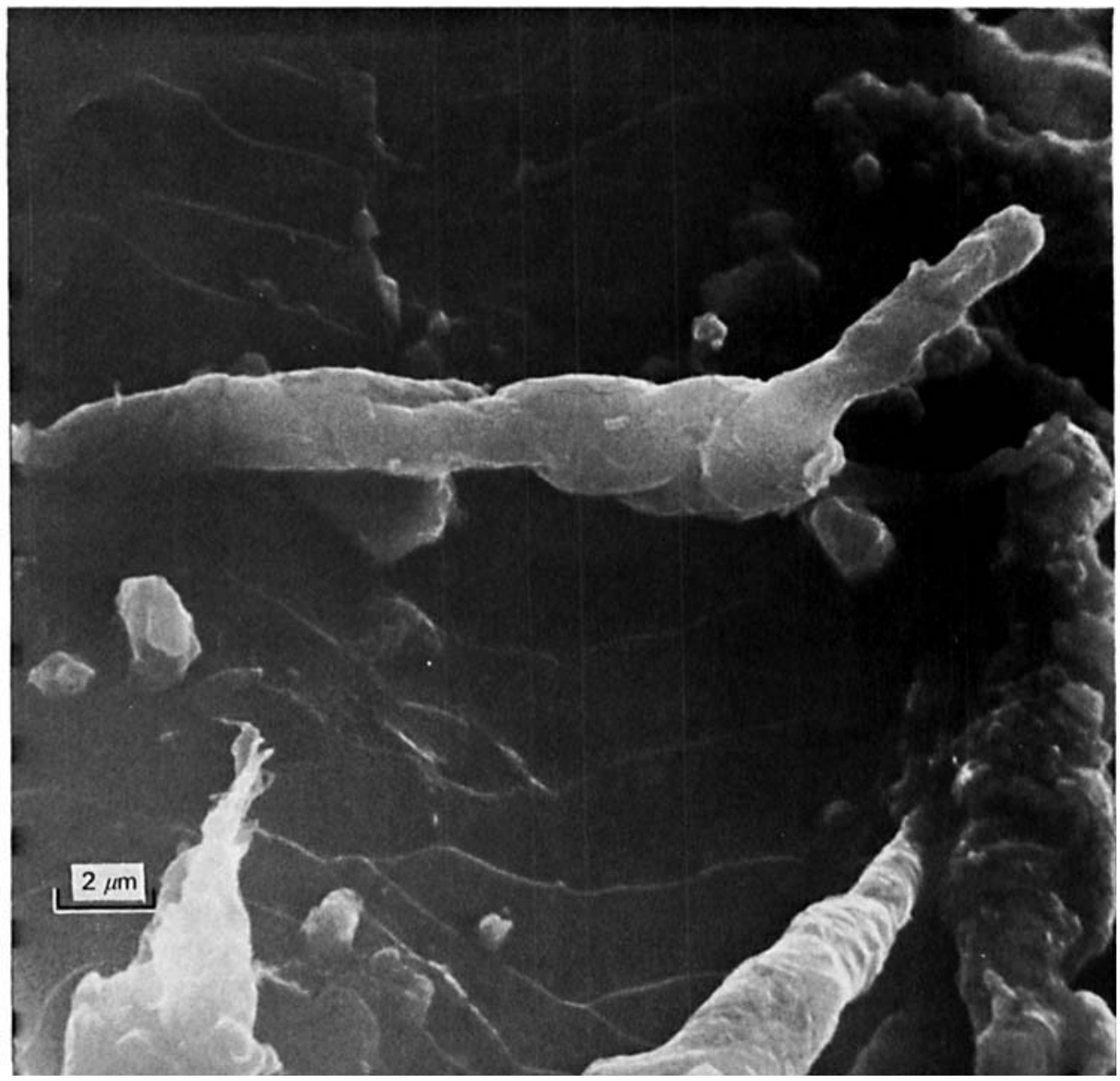

S. A. JENKINS 


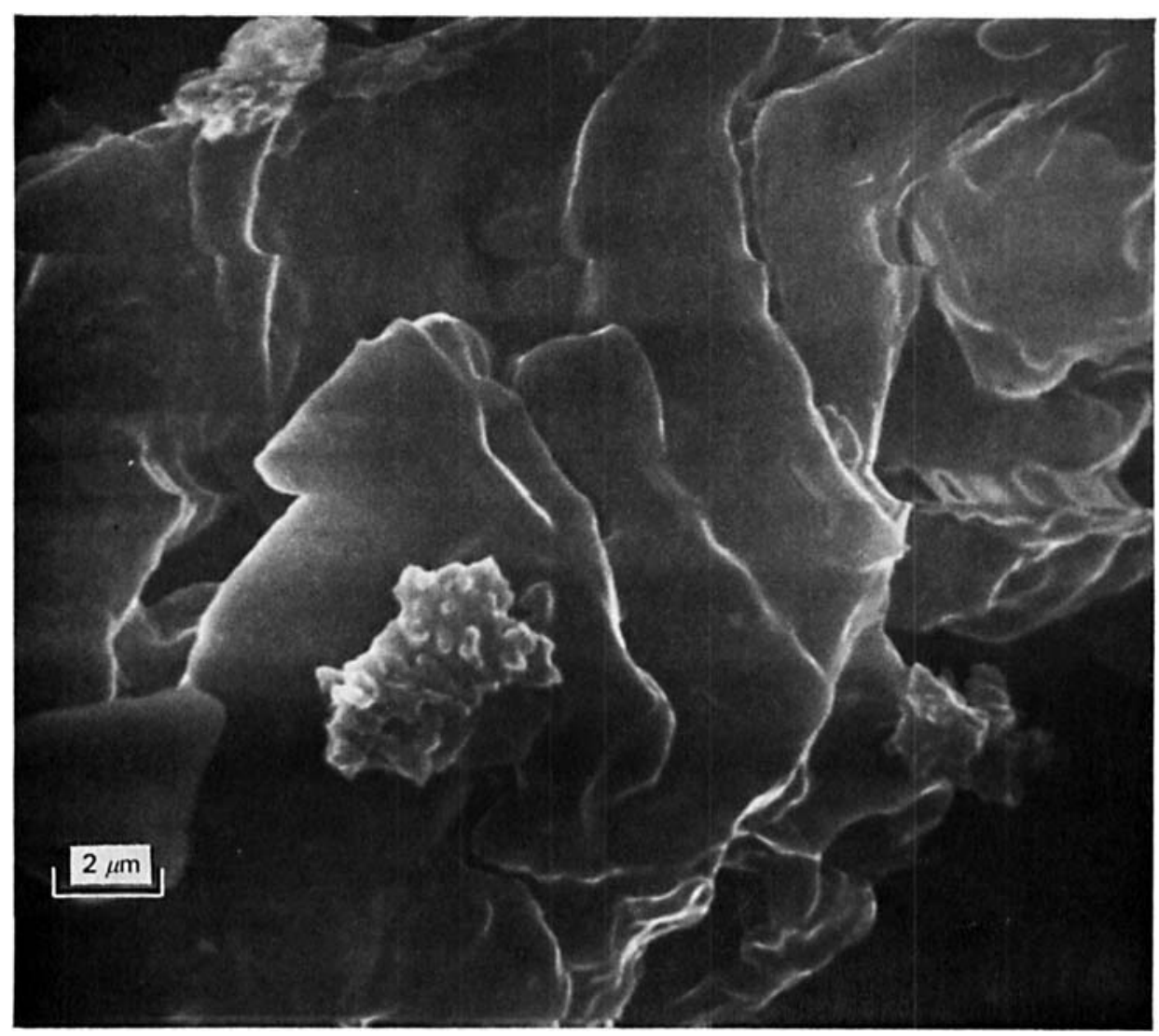

S. A. JENKINS 


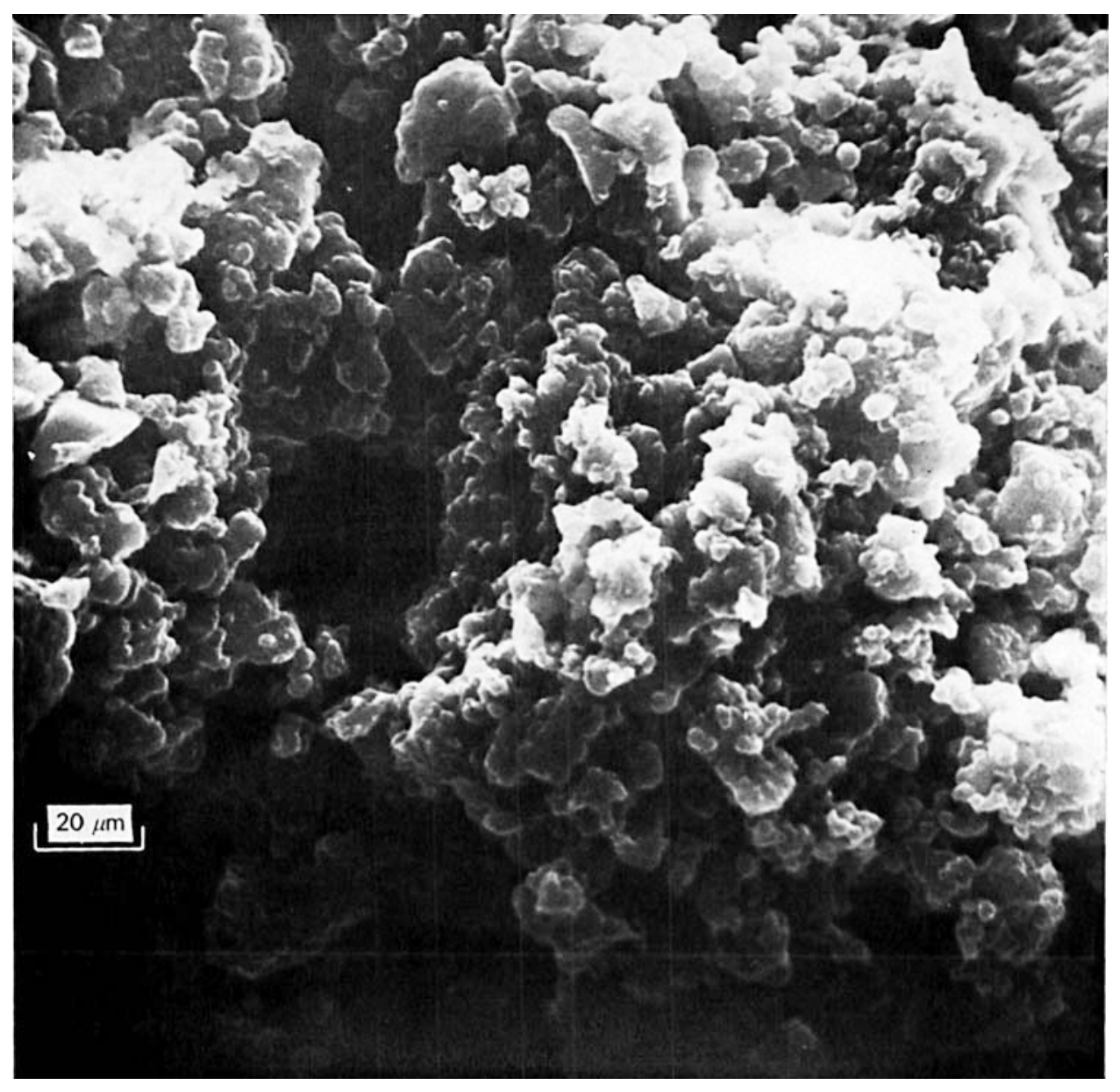

S. A. JENKINS 
British Journal of Nutrition, Vol. 40, No. 2

Plate 5

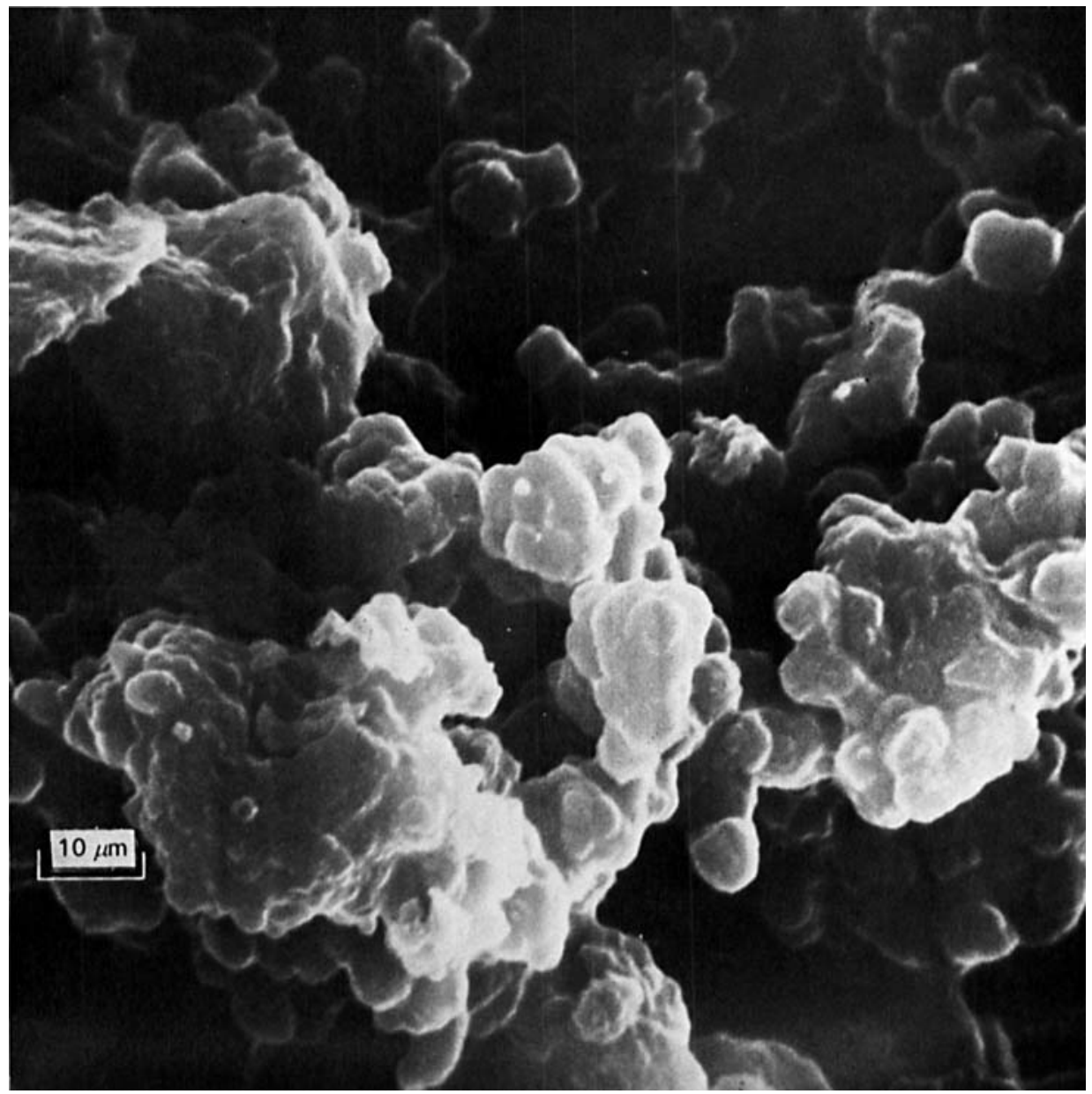

S. A. JENKINS 